\title{
EFEKTTIVITAS PENYAMPAIAN KOMUNIKASI PEMASARAN MELALUI INSTAGRAM DAN DAMPAKNYA TERHADAP KEPUTUSAN MEMBELI KONSUMEN NEGRI KOPI SARONGGE
}

\author{
Oleh: \\ Endah Lisarini*) \\ Alif Lazuardi**) \\ Email : endahlisarini@yahoo.com
}

\begin{abstract}
ABSTRAK
Salah satu literasi era industry 4.0 adalah Teknologi Informasi. Segala bentuk informasi dan komunikasi dilakukan secara digital tidak terkecuali informasi dan penyampaian penyampaian komunikasi pemasaran. Negri Kopi Sarongge menggunakan Instagram sebagai media untuk penyampaian komunikasi pemasaran produknya. Seberapa efektif penggunaan Instagram tersebut dalam mempengaruhi keputusan membeli konsuumen menjadi hal menarik untuk dikaji. Untuk itu dilakukan penelitian dengan tujuan : 1) mengkaji pengaruh kualitas penyampaian informasi pemasaran melalui media Instagram terhadap efektivitasnya; 2) mengkaji pengaruh kuantitas penyampaian informasi pemasaran melalui Instagram terhadap efektivitasnya; 3) mengkaji pengaruh kualitas dan kuantitas penyampaian komunikasi pemasaran secara simultan terhadap efektivitas penyampaian informasi pemasaran; 4) mengkaji pengaruh efektivitas penyampaian komunikasi pemasaran terhadap keputusan membeli konsumen Negri Kopi. Data primer dan data sekunder penelitian dihimpun dari 100 responden pengikut akun Instagram Negri Kopi Sarongge. Karakteristik responden secara umum adalah : didominasi laki-laki (62\%), sebagian besar berusia $21-30$ tahun $(77 \%)$, terbanyak berpendidikan S1 (61\%) dan yang paling lama mengikuti lebih dari setahun sebanyak $42 \%$. Pengikut akun Instagram merupakan populasi yang jumlahnya dapat diketahui dengan pasti pada periode waktu tertentu yang sudah ditetapkan. Oleh karena itu teknik pengambilan sampelnya secara probability random sampling dan disesuaikan dengan persyaratan jumlah sampel minimal metode analisis jalur yaitu sebanyak 100 orang. Untuk mejawab tujuan penelitian, dilakukan analisis jalur terhadap data variabel kualitas komunikasi, kuantitas komunikasi, efektivitas penyampaian komunikasi pemasaran dan keputusan membeli konsumen. Diperoleh hasil penelitian yang menyimpulkan: 1) kualitas penyampaian komunikasi pemasaran melalui Instagram berpengaruh signifikan terhadap efektivitas penyampaian komunikasi pemasaran; 2) kuantitas penyampaian komunikasi pemasaran melalui Instagram berpengaruh signifikan terhadap efektivitas penyampaian komunikasi pemasaran. Walaupun keduanya berpengaruh signifikan, namun kualitas berpengaruh lebih besar dibandingkan pengaruh kuantitas penyampaian komunikasi pemasaran melalui Instagram. Berturut-turut masing-masing sebesar 54.6\% dan 33.8\%. Hasil penelitian ke 3 menyatakan bahwa efektivitas penyampaian komunikasi pemasaran melalui Instagram berpengaruh signifikan terhadap keputusan membeli konsumen Negri Kopi Sarongge. Kondisi ini mengindikasikan bahwa penyampaian komunikasi pemasaran yang menarik dan berkelanjutan melalui media social Instagram memberikan efek positif terhadap penjualan.
\end{abstract}

Kata kunci : Instagram, Efektivitas penyampaian komunikasi pemasaran, Keputusan membeli.

\begin{tabular}{|c|c|c|}
\hline$\overline{\text { EFEKTTIVITAS }}$ & PENYAMPAIAN & $\overline{\text { ENDAH LISARINI dan ALIF LAZUARDI }}$ \\
\hline KOMUNIKASI & PEMASARAN & \\
\hline INSTAGRAM & DAMPAKNYA & \\
\hline TERHADAP & KEPUTUSAN & \\
\hline
\end{tabular}




\begin{abstract}
One of the literacy in the industrial era 4.0 is Information Technology. All forms of information and communication are carried out digitally, including information and delivery of marketing communications. Negri Kopi Sarongge uses Instagram as a medium for delivering product marketing communications. How effective the use of Instagram is in influencing consumer buying decisions is an interesting thing to study. For this reason, research was conducted with the objectives of: 1) examining the effect of the quality of delivering marketing information through Instagram media on its effectiveness; 2) examine the effect of the quantity of marketing information delivery through Instagram on its effectiveness; 3) examine the influence of the quality and quantity of the delivery of marketing communications simultaneously on the effectiveness of the delivery of marketing information; 4) examine the effect of the effectiveness of the delivery of marketing communications on consumers' buying decisions of Coffee Country. Primary data and secondary research data were collected from 100 respondents following the Negri Kopi Sarongge Instagram account. Characteristics of respondents in general are: male dominated (62\%), mostly aged 21-30 years (77\%), most have bachelor degree (61\%) and $42 \%$ have attended the longest for more than a year. Followers of an Instagram account are a population whose number can be known with certainty at a certain time period that has been set. Therefore, the sampling technique is probability random sampling and is adjusted to the requirements of the minimum sample size for the path analysis method, which is 100 people. To answer the research objectives, a path analysis was carried out on the data on the variables of communication quality, communication quantity, effectiveness of marketing communication delivery and consumer buying decisions. The results of the study concluded that: 1) the quality of delivery of marketing communications through Instagram has a significant effect on the effectiveness of the delivery of marketing communications; 2) the quantity of delivery of marketing communications through Instagram has a significant effect on the effectiveness of the delivery of marketing communications. Although both have a significant effect, the quality has a greater effect than the quantity effect of the delivery of marketing communications through Instagram. Respectively by $54.6 \%$ and $33.8 \%$. The results of the third study stated that the effectiveness of delivering marketing communications through Instagram had a significant effect on consumers' buying decisions in the Sarongge Coffee Country. This condition indicates that the delivery of attractive and sustainable marketing communications through social media Instagram has a positive effect on sales.
\end{abstract}

Keywords : Panicles of Pandanwangi, Collectors, Marketing agents.

*) Dosen Fakultas Sains Terapan UNSUR.

**) Alumni Fakultas Sains Terapan UNSUR.

\begin{tabular}{lrr}
\hline EFEKTTIVITAS & \multicolumn{2}{r}{ PENYAMPAIAN } \\
KOMUNIKASI & PEMASARAN & MELALUI \\
INSTAGRAM & DAN & DAMPAKNYA \\
TERHADAP & KEPUTUSAN & MEMBELI \\
KONSUMEN NEGRI KOPI SARONGGE
\end{tabular}

ENDAH LISARINI dan ALIF LAZUARDI 


\section{PENDAHULUAN}

Kemajuan tekonologi komunikasi pada era industry 4.0 berjalan sangat cepat baik pada perangkat lunaknya maupun pada perangkat kerasnya. Jumlah pengguna internet terus bertambah. Di Indonesia tercatat pada tahun 2018 jumlah pengguna internet mencapai 171.176 .716 orang, dengan pertumbuhan $10,12 \%$ atau sebesar 27.916.716 orang dari tahun sebelumnya (APJII, 2018). Dimensi jarak dan waktu sudah tidak menjadi kendala untuk berlangsungnya komunikasi. Keadaan ini dimanfaatkan oleh para pebisnis dalam kegiatan penyampaian komunikasi pemasarannya, tidak terkecuali Negri Kopi Sarongge.

Melalui penyampaian komunikasi pemasaran, perusahaan dapat menginformasikan, membujuk, mengingatkan konsumen baik langsung maupun tidak langsung tentang produk atau merek yang dijual. Sebaliknya seseorang dapat memberi atau menerima informasi mengenai kebutuhan, keinginan, persepsi, pengetahuan atau pernyataan sikap (Kotler dan Amstrong, 2008; Kotler et al, 2012; Clow \& Back, 2014). Penyampaian komunikasi pemasaran tidak hanya melibatkan pemberi dan penerima informasi saja, melainkan juga materi komunikasi dan media untuk menyampaikannya. Karena melibatkan banyak pihak, maka penyampaian komunikasi pemasaran disebut juga sebagai Integrated Marketing Communication (IMC). IMC dapat dilakukan melalui bauran penyampaian komunikasi pemasaran yaitu : iklan, promosi penjualan, public relation, penjualan langsung, penjualan personal, sosial media,dll (Edhole III, 2013 : 7; Olpengujianmi Kayode, 2014).

Efektivitas penyampaian komunikasi pemasaran dapat berpengaruh kepada perilaku konsumen. Apakah konsumen hanya berminat saja pada suatu produk atau sampai memutuskan untuk membeli. Perilaku konsumen yang terdiri dari pengetahuan, sikap dan tingkah laku dapat dijadikan indikator efektivitas penyampaian komunikasi pemasaran (Dwinanda, dkk., 2018). Menarik tidaknya dan tersampaikan tidaknya maksud dari penyampaian komunikasi pemasaran dipengaruhi oleh kualitas dan kuantitas komunikasi itu sendiri. Komunikasi akan berjalan dengan baik apabila pesan mudah dipahami, komunikasi dalam intonasi dan tempo yang tepat serta dilakukan secara terus menerus (Nurrahman dkk., 2019). Hal inilah yang mendasari penulis melakukan kajian mengenai pengaruh kualitas dan kuantitas penyampaian komunikasi pemasaran terhadap efektivitas penyampaian komunikasi pemasaran, yang pada gilirannya berpengaruh pada keputusan membeli konsumen. Penyampaian komunikasi pemasaran itu sendiri memerlukan media penyampaian. Pada saat sekarang ini, media yang banyak digunakan adalah media komunikasi sosial.

Media komunikasi sosial digital merupakan media komunikasi modern memuat konten informasi yang sengaja dibuat oleh orang sehingga sangat mudah untuk diakses dan dimaksudkan untuk memfasilitasi kegiatan penyampaian komunikasi pemasaran, komunikasi publik, mempengaruhi, dan berinteraksi dengan sesama dan dengan khalayak umum (Setiadi, 2016). Media social marketing berpusat pada usaha

\begin{tabular}{|c|c|c|}
\hline EFEKTTIVITAS & PENYAMPAIAN & $\overline{\text { ENDAH LISARINI dan ALIF LAZUARDI }}$ \\
\hline KOMUNIKASI & PEMASARAN & \\
\hline INSTAGRAM & DAMPAKNYA & \\
\hline TERHADAP & KEPUTUSAN & \\
\hline
\end{tabular}


membuat konten-konten yang menarik perhatian dan memdorong pembaca untuk berinteraksi serta membagikannya dalam lingkungan jejaring sosial pertemanan atau internet. Internet merupakan sebuah sistem jaringan yang menghubungkan berbagai komputer dari berbagai belahan dunia untuk saling terhubung dan bertukar data serta bertukar informasi (Agung dalam Jubilee Enterprise, 2010). Media penyampaian komunikasi pemasaran melalui internet anatara lain melalui facebook, twitter, instagram dan pemasaran viral seperti email dan blog.

Penelitian dilakukan dengan tujuan : 1) mengkaji pengaruh kualitas penyampaian komunikasi pemasaran melalui Instagram terhadap efektivitas penyampaian komunikasi pemasaran; 2) mengkaji pengaruh kuantitas penyampaian komunikasi pemasaran melalui Instagram terhadap efektivitas penyampaian komunikasi pemasaran; 3) mengkaji pengaruh kualitas dan kuantitas penyampaian komunikasi pemasaran secara simultan terhadap efektivitas penyampaian komunikasi pemasaran; 4) mengkaji pengaruh efektivitas penyampaian komunikasi pemasaran terhadap keputusan membeli konsumen Negri Kopi. Pada akhirnya hasil penelitian dapat dijadikan masukan rekomendasi bagi Negri Kopi dalam memanfaatkan Instagram sebagai media untuk menginformasikan mengenai perusahaan, produk dan penjualannya.

\section{METODE PENELITIAN}

Untuk mendapatkan data primer, dilakukan observasi dan wawancara kepada pemilik Negri Kopi Sarongge serta pengisian kuesioner oleh 100 responden pengikut Instagram Negri Kopi@Negrikopi. Data tanggapan diperoleh dari 100 responden yang ditentukan dengan teknik probability random sampling. Teknik ini diambil karena jumlah populasi pengikut Instagram Negri Kopi diketahui dengan pasti.

Variabel yang dikaji dalam penelitian ini meliputi: kualitas penyampaian komunikasi pemasaran, kuantitas penyampaian komunikasi pemasaran, efektivitas penyampaian komunikasi pemasaran dan keputusan membeli. Kualitas penyampaian komunikasi pemasaran diukur melalui indikator : konten yang menarik, informasi disampaikan dengan baik, kesesuaian caption dengan konten, produk yang dijual tidak melanggar asusila. Sementara kuantitas penyampaian komunikasi pemasaran diukur dengan indikator: seberapa sering mengunggah konten pada Feed Instagram, seberapa sering menggunggah konten di Instastory. Variabel efektivitas penyampaian komunikasi pemasaran diukur dengan indikator: membentuk kesadaran informasi, mengubah pikiran komunikan, memberi pengaruh untuk melakukan tindakan dan melakukan sesuatu tindakan dengan cara tertentu. Pada akhirnya variabel keputusan membeli diukur melalui indikator: memutuskan melakukan pembelian dan tidak melakukan pembelian. Seseorang akan memutuskan untuk membeli suatu produk atau tidak, setelah melalui tahap-tahap proses yang diawali dengan pengenalan kebutuhan, pencarian informasi terkait produk yang akan dibeli, pengevaluasian

\begin{tabular}{|c|c|c|}
\hline EFEKTTIVITAS & PENYAMPAIAN & $\overline{\text { ENDAH LISARINI dan ALIF LAZUARDI }}$ \\
\hline KOMUNIKASI & PEMASARAN & \\
\hline INSTAGRAM & DAMPAKNYA & \\
\hline TERHADAP & KEPUTUSAN & \\
\hline
\end{tabular}


alternatif sampai keputusan membeli. Informasi yang dicari, diperoleh hingga dievaluasi mempengaruhi keputusan akhir yang diambil (Solomon et al, 2006). Oleh karena itu, informasi pemasaran yang disampaikan oleh penjual atau produsen sebagai penyampaian komunikasi pemasaran diduga juga akan berpengaruh pada keputusan membeli. Pada era digitalisasi sekarang ini, penyampaian komunikasi pemasaran dapat disampaikan melalui berbagai media termasuk media komunikasi sosial atau media online untuk membangun kepedulian dan perhatian pelanggan (Idana, 2018). Pada penggunaan media online sebagai media penyampaian komunikasi pemasaran perlu diperhatikan context, communication, collaboration, connection (Heuer dalam Kinanti dan Putri, 2017) agar komunikasi berjalan efektif. Efektivitas dari komunikasi adalah suatu ukuran yang menyatakan seberapa jauh pesan komunikasi diterima baik oleh penerima pesan dan memberikan efek sesuai dengan harapan penyampai pesan (Hardjana, 2000). Pesan yang tersampaikan dapat mempengaruhi Keputusan pembelian konsumen adalah proses mengintegratsikan yang mengkombinasikan pengetahuan untuk mengevaluasi dua alternatif atau lebih, dan memilih salah satu di antaranya (Schiffman \& Kanuk, 2007; Hanum dkk., 2017). Secara rinci, operasional variabel peneperilaku penerima pesanlitian dapat dilihat pada Tabel 1.

\begin{tabular}{|c|c|c|}
\hline EFEKTTIVITAS & PENYAMPAIAN & $\overline{\text { ENDAH LISARINI dan ALIF LAZUARDI }}$ \\
\hline KOMUNIKASI & PEMASARAN & \\
\hline INSTAGRAM & DAMPAKNYA & \\
\hline TERHADAP & KEPUTUSAN & \\
\hline
\end{tabular}


Tabel. Operasional variabel penelitian.

\begin{tabular}{|c|c|c|c|}
\hline $\begin{array}{c}\text { Variabel } \\
\text { Penelitian }\end{array}$ & Konsep Variabel & Indikator & Skala \\
\hline $\begin{array}{l}\text { Kualitas } \\
\text { Komunikasi } \\
\left(\mathrm{X}_{1}\right)\end{array}$ & $\begin{array}{l}\text { Media komunikasi sosial adalah konten } \\
\text { yang berisi informasi yang sengaja } \\
\text { dibuat supaya mudah diakses dan } \\
\text { dimaksudkan untuk memfasilitasi } \\
\text { kegiatan komunikasi, mempengaruhi, } \\
\text { dan berinteraksi serta dapat membangun } \\
\text { identitas visual bisnis (Untari dkk., } \\
\text { 2018). Larangan memuat informasi atau } \\
\text { dokumen elektronik yang melanggar } \\
\text { kesusilaan (UU ITE Nomor 11, 2008) }\end{array}$ & $\begin{array}{l}\text { - Konten yang } \\
\text { menarik; } \\
\text { - Informasi yang baik } \\
\text { - Caption sesuai } \\
\text { dengan konten } \\
\text { - Produk yang dijual } \\
\text { tidak melanggar } \\
\text { asusila }\end{array}$ & $\begin{array}{l}\text { Ordina } \\
1\end{array}$ \\
\hline $\begin{array}{l}\text { Kuantitas } \\
\text { Komunikasi } \\
\left(\mathrm{X}_{1}\right)\end{array}$ & $\begin{array}{l}\text { Komunikasi akan berjalan dengan baik } \\
\text { apabila dilakukan dalam fitur-fitur, } \\
\text { durasi dan tempo yang tepat serta } \\
\text { dilakukan secara terus menerus } \\
\text { (Nurrahman dkk., 2019). }\end{array}$ & $\begin{array}{l}\text { - Seberapa sering } \\
\text { mengunggah } \\
\text { konten pada Feed } \\
\text { instagram } \\
\text { - Seberapa sering } \\
\text { menggunggah } \\
\text { konten di Instastory }\end{array}$ & $\begin{array}{l}\text { Ordina } \\
1\end{array}$ \\
\hline $\begin{array}{l}\text { Efektivitas } \\
\text { dari } \\
\text { komunikasi } \\
(\mathrm{Y})\end{array}$ & $\begin{array}{l}\text { Efektivitas dari komunikasi adalah suatu } \\
\text { ukuran yang menyatakan seberapa jauh } \\
\text { pesan komunikasi diterima baik oleh } \\
\text { penerima pesan dan memberikan efek } \\
\text { sesuai dengan harapan penyampai pesan. } \\
\text { Efek dari pesan meliputi : Efek kognitif } \\
\text { yaitu membentuk kesadaran informasi. } \\
\text { Pesan yang disampaikan bertujuan untuk } \\
\text { mengubah pikiran komunikan; Efek } \\
\text { afektif yaitu memberi pengaruh untuk } \\
\text { melakukan sesuatu kemudian } \\
\text { menimbulkan perasaan tertentu; Konatif } \\
\text { yaitu membentuk pola khalayak menjadi } \\
\text { perilaku selanjutnya untuk melakukan } \\
\text { sesuatu dengan cara tertentu (Dwinanda, } \\
\text { dkk., 2018) }\end{array}$ & $\begin{array}{l}\text { - Membentuk } \\
\text { kesadaran informasi } \\
\text { - Mengubah pikiran } \\
\text { komunikan } \\
\text { - Memberi pengaruh } \\
\text { untuk melakukan } \\
\text { tindakan } \\
\text { - Melakukan sesuatu } \\
\text { tindakan dengan } \\
\text { cara tertentu }\end{array}$ & $\begin{array}{l}\text { Ordina } \\
1\end{array}$ \\
\hline $\begin{array}{l}\text { Keputusan } \\
\text { membeli } \\
(\mathrm{Z})\end{array}$ & $\begin{array}{l}\text { Keputusan pembelian konsumen adalah } \\
\text { proses mengintegratsikan yang } \\
\text { mengkombinasikan pengetahuan untuk } \\
\text { mengevaluasi dua alternatif atau lebih, } \\
\text { dan memilih salah satu di antaranya } \\
\text { (Schiffman \& Kanuk, 2007; Hanum } \\
\text { dkk., 2018) }\end{array}$ & $\begin{array}{l}\text { - Memutuskan } \\
\text { membeli } \\
\text { - Memutuskan tidak } \\
\text { membeli }\end{array}$ & $\begin{array}{l}\text { Ordina } \\
1\end{array}$ \\
\hline
\end{tabular}

Tanggapan dari responden berupa jawaban dengan skala ordinal dari Sangat Setuju (skala 5) sampai Sangat Tidak Setuju (skala 1). Seluruh data tanggapan yang terkumpul, selanjutnya dipengujian validitas, reliabilitas, normalitas dan Confirmatory Factor Analysis (CFA) sebelum pada akhirnya dianalis jalur.

\begin{tabular}{|c|c|c|}
\hline EFEKTTIVITAS & PENYAMPAIAN & ENDAH LISARINI dan ALIF LAZUARD \\
\hline KOMUNIKASI & PEMASARAN MELALUI & \\
\hline INSTAGRAM & DAMPAKNYA & \\
\hline TERHADAP & KEPUTUSAN MEMBELI & \\
\hline
\end{tabular}




\section{HASIL DAN PEMBAHASAN}

Negri Kopi adalah sebuah tempat usaha hasil perkebunan kopi yang bertujuan untuk menampung hasil panen kopi oleh para petani yang ada di sekitar Sarongge Desa Ciputri Kecamatan Pacet Cianjur Jawa Barat. Produk yang dihasilkan berupa aneka macam varian kopi antara lain green bean, full wash dan sejumlah kopi dengan merek dagang beragam. Dalam memasarkan produknya, Negri Kopi menggunakan media komunikasi sosial untuk keperluan penyampaian informasi pemasarannya maupun penjualan produknya. Media komunikasi sosial yang digunakan adalah Instagram. Instagram adalah salah satu jenis media komunikasi sosial yang merupakan suatu jejaring sosial media yang dapat digunakan melalui sistem operasi pada ponsel berbasis iOS, Android, dan Windows Phone. Di dalam Instagram terdapat fitur instastory yang digunakan untuk mengunggah aktivitas harian selama 24 jam, dan instagram live, yang dapat digunakan untuk membuat konten dengan siaran waktu secara langsung (Sarastuti, 2017).

Sebanyak 100 orang pengikut akun Instagram Negri Kopi yang dijadikan responden dalam penelitian ini memiliki karakteristik sebagai berikut. Responden yang ada didominasi oleh laki-laki dengan rentang usia 21 - 30 tahun, di jenjang pendidikan strata 1 dan sudah lebih dari satu tahun telah mengikuti akun Instagram Negri Kopi. Fakta ini menunjukkan bahwa kopi sebagai salah satu produk minuman masih diminati oleh sebagian besar kaum laki-laki. Tidak sekedar minuman semata, namun kopi sudah menjadi bagian dari gaya hidup. Oleh karena itu, para kaum muda usia produktif banyak yang menyukai kopi dan aktif mengikuti perkembangan informasi di Instagram. Karakteristik 100 responden dapat dilihat pada Gambar 1 4.

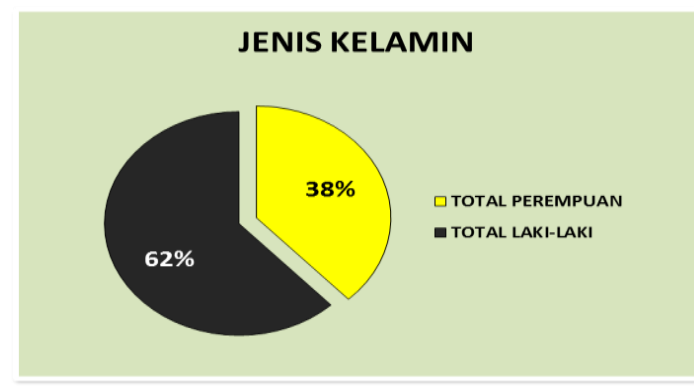

Gambar 1. Jenis kelamin responden.

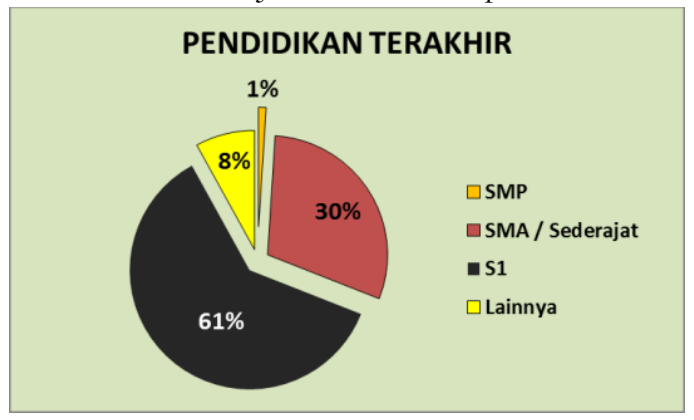

Gambar 3. Pendidikan terakhir responden.

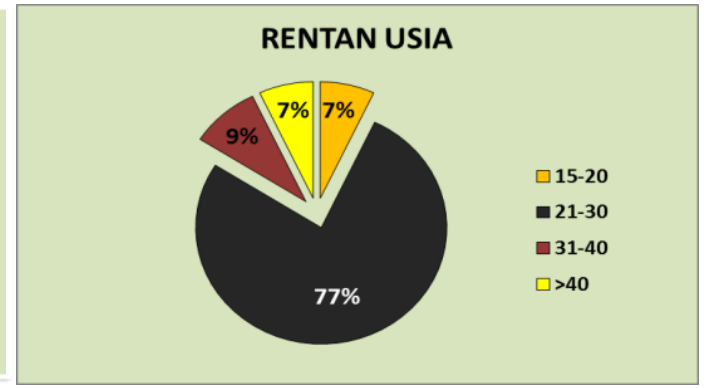

Gambar 2. Rentang usia responden.

LAMA MENGIKUTI @NEGRIKOPI

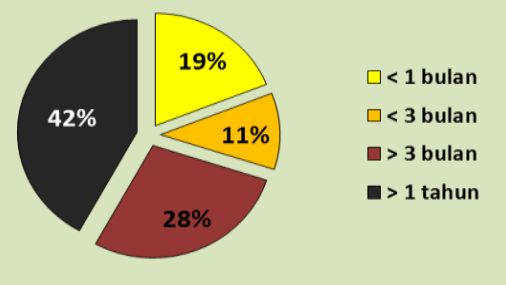

Gambar 4. Lamanya mengikuti instagram.

\begin{tabular}{lrr}
\hline EFEKTTIVITAS & \multicolumn{2}{r}{ PENYAMPAIAN } \\
KOMUNIKASI & PEMASARAN & MELALUI \\
INSTAGRAM & DAN & DAMPAKNYA \\
TERHADAP & KEPUTUSAN & MEMBELI \\
KONSUMEN NEGRI KOPI SARONGGE
\end{tabular}

ENDAH LISARINI dan ALIF LAZUARDI

KONSUMEN NEGRI KOPI SARONGGE 
Untuk mengetahui apakah pernyataan pada kuesioner telah mengungkapkan dan mengukur idikator variabel, maka dilakukan pengujian validitas (Ghozali, 2018). Data dinyatakan valid apabila $r$ hitung $\geq$ cut-off sebesar 0,5 (Arikunto, 2006). Setelah dipengujian validitasnya, data tanggapan dari responden dinyatakan seluruhnya valid berturut-turut seperti pada Tabel $1-4$.

Tabel 1. Hasil pengujian validitas Kualitas Penyampaian komunikasi pemasaran $\left(\mathrm{X}_{1}\right)$.

\begin{tabular}{cccc}
\hline Item & Koefisien Validitas & Cut Off & Kesimpulan \\
\hline $\mathbf{X}_{1.1}$ & 0.787 & 0.5 & Valid \\
$\mathbf{X}_{1.2}$ & 0.700 & 0.5 & Valid \\
$\mathbf{X}_{1.3}$ & 0.674 & 0.5 & Valid \\
$\mathbf{X}_{1.4}$ & 0.583 & 0.5 & Valid \\
$\mathbf{X}_{1.5}$ & 0.636 & 0.5 & Valid \\
$\mathbf{X}_{1.6}$ & 0.534 & 0.5 & Valid \\
$\mathbf{X}_{1.7}$ & 0.622 & 0.5 & Valid \\
\hline
\end{tabular}

Tujuh item pernyataan pada kuesioner dinyatakan valid. Hal ini menunjukkan bahwa seluruh pernyataan tersebut sudah mengukur indikator variabel penelitian Kualitas Penyampaian komunikasi pemasaran dan data yang diperoleh dapat diolah lanjut. Hal serupa berlaku pada pengujian validitas variabel Kuantitas Penyampaian komunikasi pemasaran. Walaupun kedua variabel eksogen dinyatakan valid, namun validitas Kuantitas Penyampaian komunikasi pemasaran lebih tinggi dibandingkan dengan validitas Kualitas Penyampaian komunikasi pemasaran.

Tabel 2. Hasil pengujian validitas Kuantitas Penyampaian komunikasi pemasaran $\left(\mathrm{X}_{2}\right)$.

\begin{tabular}{cccc}
\hline Item & Koefisien Validitas & Cut Off & Kesimpulan \\
\hline $\mathbf{X}_{2.1}$ & 0.626 & 0.5 & Valid \\
$\mathbf{X}_{2.2}$ & 0.752 & 0.5 & Valid \\
$\mathbf{X}_{2.3}$ & 0.718 & 0.5 & Valid \\
$\mathbf{X}_{2.4}$ & 0.758 & 0.5 & Valid \\
\hline
\end{tabular}

Seluruh indikator variabel untuk mengukur Efektivitas Penyampaian komunikasi pemasaran juga dinyatakan valid dan dapat diolah lanjut. Variabel ini dijadikan variabel intervening. Diduga calon konsumen akan memutuskan pembeliannya setelah mendapatkan informasi. Informasi yang efektif, akan mempengaruhi perilaku konsumen.

Tabel 3. Hasil pengujian validitas Efektivitas Penyampaian komunikasi pemasaran (Y).

\begin{tabular}{|c|c|c|c|}
\hline Item & Koefisien Validitas & Cut Off & Kesimpulan \\
\hline$Y_{.1}$ & 0.635 & 0.5 & Valid \\
\hline $\mathbf{Y}_{.2}$ & 0.653 & 0.5 & Valid \\
\hline Y.3 & 0.722 & 0.5 & Valid \\
\hline Y.4 & 0.766 & 0.5 & Valid \\
\hline Y.5 & 0.620 & 0.5 & Valid \\
\hline Y.6 & 0.605 & 0.5 & Valid \\
\hline $\mathbf{Y}_{.7}$ & 0.658 & 0.5 & Valid \\
\hline
\end{tabular}

\begin{tabular}{lrr}
\hline EFEKTTIVITAS & \multicolumn{2}{r}{ PENYAMPAIAN } \\
KOMUNIKASI & PEMASARAN & MELALUI \\
INSTAGRAM & DAN & DAMPAKNYA \\
TERHADAP & KEPUTUSAN & MEMBELI \\
KONSUMEN NEGRI KOPI SARONGGE
\end{tabular}

ENDAH LISARINI dan ALIF LAZUARDI 
Hasil pengujian validitas terhadap indikator variabel untuk mengukur variabel Keputusan Membeli Konsumen seluruhnya dinyatakan valid sehingga seluruh data dapat diproses lanjut. Selanjutnya seluruh indikator variabel yang sudah valid, dilanjutkan dipengujian reliabilitasnya. Konsistensi tanggapan dari responden atas pernyataan pada kuesioner dipengujian reliabilitasnya. Apabila Cronbach's coefficient alpha (a) > 0.7 maka cronbach's alpha acceptable (construct reliable) atau tanggapan dari responden atas pertanyaan dalam kuesioner layak diproses lanjut. Hasil pengujian reliabilitas seluruh variabel penelitian terdapat pada Tabel 5.

Tabel 4. Hasil pengujian validitas Keputusan Membeli Konsumen (Z)

\begin{tabular}{cccc}
\hline Item & Koefisien Validitas & Cut off & Kesimpulan \\
\hline $\mathbf{Z}_{1}$ & 0.651 & 0.5 & Valid \\
$\mathbf{Z}_{2}$ & 0.637 & 0.5 & Valid \\
$\mathbf{Z}_{3}$ & 0.682 & 0.5 & Valid \\
$\mathbf{Z}_{4}$ & 0.765 & 0.5 & Valid \\
\hline
\end{tabular}

Dari Tabel 5 dapat diketahui bahwa ke empat variabel laten penelitian dinyatakan reliabel. Hasil ini memberikan arti bahwa keseluruhan data dapat diproses lanjut untuk dipengujian normalitasnya. Pengujian normalitas data digunakan untuk mengetahui apakah data yang terkumpul mempunyai pola sebaran normal dan data berdistribusi normal diperlukan agar data hasil analisis tidak bias. Data yang mempunyai sebaran normal juga memungkinkan untuk diambil kesimpulan secara general. Hasil pengujian normalitas dapt dilihat pada Tabel 6.

Tabel 5. Hasil pengujian reliabilitas variabel penelitian.

\begin{tabular}{cccc}
\hline Variabel & Cronbach's Alpa Coefficient & Cut Off & Kesimpulan \\
\hline $\mathbf{X}_{\mathbf{1}}$ & 0.869 & 0.7 & Reliabel \\
$\mathbf{X}_{\mathbf{2}}$ & 0.863 & 0.7 & Reliabel \\
$\mathbf{Y}$ & 0.880 & 0.7 & Reliabel \\
$\mathbf{Z}$ & 0.845 & 0.7 & Reliabel \\
\hline
\end{tabular}

Tabel 6. Hasil pengujian normalitas variabel penelitian.

One-Sample Kolmogorov-Smirnov Test

\begin{tabular}{llr}
\hline $\mathrm{N}$ & & Standardized Residual \\
Normal Parameters & & 97 \\
& Mean & .0000000 \\
Most Extreme Differences & Std. Deviation & .98425098 \\
& Absolute & .068 \\
& Positive & .063 \\
& Negative & -.068 \\
\hline Test Statistic & & .068 \\
\hline Asymp. Sig. (2-tailed) & & $\mathbf{. 2 0 0}$ \\
\hline
\end{tabular}

Dari Tabel 6 dapat diketahui bahwa data tersebut dinyatakan memenuhi sebaran normal karena nilai signifikansi yang diperoleh sebesar $0.200>0.05$, maka dapat disimpulkan bahwa nilai residual berdistribusi normal dan data bisa digunakan untuk pengujian selanjutnya. Setelah semua data memenuhi validitas, reliabilitas dan

\begin{tabular}{|c|c|c|}
\hline EFEKTTIVITAS & PENYAMPAIAN & ENDAH LISARINI dan ALIF LAZUARDI \\
\hline KOMUNIKASI & PEMASARAN & \\
\hline INSTAGRAM & DAN DAMPAKNYA & \\
\hline TERHADAP & KEPUTUSAN MEMBELI & \\
\hline
\end{tabular}


normalitas, maka seluruhnya akan dipengujian dengan Confirmatory Factor Analysis (CFA) untuk memastikan apakah indikator-indikator variabel yang digunakan dapat mengkonfirmasikan faktor-faktor utama yang paling mempengaruhi variabel dependen dari serangkaian pengujian yang dilakukan atas serangkaian variabel independen sebagai faktornya (Widodo, 2006). CFA juga dilakukan untuk mengetahui apakah variabel-variabel independen megelompok sebagai satu faktor atau lebih. Setelah melalui tahap-tahap pengpengujianan CFA, didapatkan bahwa seluruh indikator variabel $\mathrm{X}_{1}\left(\mathrm{X}_{1.1}-\mathrm{X}_{1 \cdot 7}\right)$ mengelompok sebagai satu faktor $\mathrm{X}_{1}$. Sementara seluruh indikator variabel $\mathrm{X}_{2}\left(\mathrm{X}_{2.1}-\mathrm{X}_{2.4}\right)$ mengelompok sebagai satu faktor lainnya yaitu faktor $\mathrm{X}_{2}$. Hasil ini dapat dilihat pada Tabel 7. Besarnya korelasi antara factor 1 dengan factor 2 dapat dilihat pada Tabel 8 .

Tabel 7. Rotated Component Matrix. Tabel 8. Component transformation matrix

\begin{tabular}{|c|c|c|}
\hline & \multicolumn{2}{|c|}{ Component } \\
\hline & 1 & 2 \\
\hline $\mathrm{X}_{1.1}$ & .539 & .635 \\
\hline $\mathrm{X}_{1.2}$ & .560 & .569 \\
\hline $\mathrm{X}_{1.3}$ & 288 & .739 \\
\hline $\mathrm{X}_{1.4}$ & .097 & .762 \\
\hline $\mathrm{X}_{1.5}$ & 137 & .779 \\
\hline $\mathrm{X}_{1.6}$ & 193 & .672 \\
\hline $\mathrm{X}_{1.7}$ & .435 & .511 \\
\hline $\mathrm{X}_{2.1}$ & .789 & .083 \\
\hline $\mathrm{X}_{2.2}$ & .862 & . 197 \\
\hline $\mathrm{X}_{2.3}$ & .749 & .354 \\
\hline $\mathrm{X}_{2.4}$ & .781 & 237 \\
\hline
\end{tabular}

\begin{tabular}{lcc}
\hline Component & 1 & 2 \\
\hline 1 & .714 & .701 \\
\hline 2 & -.701 & .714 \\
\hline Extraction Method: Principal Component \\
Analysis. \\
Rotation Method: Varimax with Kaiser \\
Normalization.
\end{tabular}

Untuk menjawab tujuan penelitian 1 - 4, dilakukan analisis jalur dengan terlebih dahulu dilakukan pengujian $\mathrm{t}$, pengujian $\mathrm{F}$ dan penghitungan koefisien determinan. Pengujian t dilakukan untuk mengetahui pengaruh parsial variabel bebas kualitas penyampaian komunikasi pemasaran melalui Instagram terhadap efektivitas penyampaian komunikasi pemasaran dan pengaruh kuantitas penyampaian komunikasi pemasaran melalui Instagram terhadap efektivitas penyampaian komunikasi pemasaran serta pengaruh efektivitas penyampaian komunikasi pemasaran melalui Instagram terhadap keputusan membeli konsumen. Sementara pengujian $\mathrm{F}$ dilakukan untuk mengkaji pengaruh simultan kualitas dan kuantitas penyampaian komunikasi pemasaran melalui Instagram terhadap efektivitas penyampaian komunikasi pemasaran. Hasil pengujian t ditunjukkan pada Tabel 9 dan 10, sedangkan hasil pengujian F pada Tabel 11.

\begin{tabular}{|c|c|c|}
\hline$\overline{\text { EFEKTTIVITAS }}$ & PENYAMPAIAN & ENDAH LISARINI dan ALIF LAZUARDI \\
\hline KOMUNIKASI & PEMASARAN & \\
\hline INSTAGRAM & DAMPAKNYA & \\
\hline TERHADAP & KEPUTUSAN MEMBELI & \\
\hline
\end{tabular}


Tabel 9. Pengaruh parsial kualitas dan kuantitas komunikasi melalui Instagram terhadap efektivitas penyampaian komunikasi pemasaran.

\section{Coefficients $^{a}$}

\begin{tabular}{|c|c|c|c|c|c|c|}
\hline & \multirow{2}{*}{ Model } & \multicolumn{2}{|c|}{$\begin{array}{l}\text { Unstandardized } \\
\text { Coefficients }\end{array}$} & \multirow{2}{*}{$\begin{array}{c}\begin{array}{c}\text { Standardized } \\
\text { Coefficients }\end{array} \\
\text { Beta }\end{array}$} & \multirow[b]{2}{*}{$\mathrm{t}$} & \multirow{2}{*}{ Sig. } \\
\hline & & B & $\begin{array}{l}\text { Std. } \\
\text { Error }\end{array}$ & & & \\
\hline \multirow[t]{5}{*}{1} & (Constant) & 5.636 & 1.879 & & 3.000 & .003 \\
\hline & Kualitas & .551 & .080 & .546 & 6.902 & .000 \\
\hline & Komunikasi & & & & & \\
\hline & Kuantitas & .470 & .110 & .338 & 4.271 & .000 \\
\hline & Komunikasi & & & & & \\
\hline
\end{tabular}

a. Dependent Variable: Efektivitas dari komunikasi.

Kualitas maupun kuantitas penyampaian komunikasi pemasaran melalui instagram secara parsial memberikan pengaruh signifikan terhadap efektivitas penyampaian komunikasi pemasaran walaupun lebih besar pengaruh kualitas daripada kuantitas. Ternyata konten yang menarik, sesuai dengan caption, tidak melanggar kesusilaan menjadi hal penting bagi calon konsumen untuk mendapatkan informasi mengenai perusahaan Negri Kopi, produknya dan cara mendapatkan produk tersebut. Hal ini lebih efektif dibandingkan kuantitas atau frekuensi informasi tersebut diunggah ulang (Tabel 9). Sebesar 0.546 efektivitas penyampaian komunikasi pemasaran dipengaruhi oleh kulaitas komunikasi sementara hanya 0.338 dipengaruhi oleh kuantitas komunikasi. Efektivitas kualitas komunikasi melalui Instagram dibuktikan dengan pengaruhnya secara signifikan sebesar 0.802 terhadap fikiran, sikap dan perilaku calon konsumen untuk pada akhirnya melakukan tindakan melakukan pembelian produk (Tabel 10). Kualitas dan kuantitas komunikasi melalui Instagram secara simultan berpengaruh signifikan terhadap efektivitas penyampaian komunikasi pemasaran (Tabel 11). Hasil ini mendukung pendapat Wulandari dkk. (2013) bahwa tidak hanya kualitas berupa kesesuaian konten Instagram dengan pesan saja melainkan diperlukan adanya intensitas unggahan agar pengikut Instagram terpengaruh fikiran, sikap dan perilakunya. Konten Instagram memuat informasi mengenai perusahaan Negri Kopi, produk kopi berbagai varian dan dimana saja para calon pelanggan dapat membeli atau menikmati kopinya. Selain itu terdapat instastory dan Instagram live yang mengunggah aktivitas harian Negri Kopi. Melalui media komunikasi Instagram yang memenuhi kualitas dan kuantitas, pengikut Instagram Negri Kopi terus bertambah dari waktu ke waktu. Hal ini menunjukkan bahwa penyampaian komunikasi pemasaran melalui Instagram berjalan efektif. Efektivitas penyampaian komunikasi pemasaran Instagram juga terbukti berpengaruh signifikan terhadap keputusan membeli konsumen (Tabel 10).

\begin{tabular}{|c|c|c|}
\hline$\overline{\text { EFEKTTIVITAS }}$ & PENYAMPAIAN & $\overline{\text { ENDAH LISARINI dan ALIF LAZUARDI }}$ \\
\hline KOMUNIKASI & PEMASARAN MELALUI & \\
\hline INSTAGRAM & DAMPAKNYA & \\
\hline TERHADAP & KEPUTUSAN MEMBELI & \\
\hline
\end{tabular}


Tabel 10. Pengaruh parsial efektivitas penyampaian komunikasi pemasaran melalui Instagram terhadap keputusan membeli konsumen

\section{Coefficients $^{a}$}

\begin{tabular}{lllllll}
\hline \multirow{2}{*}{ Model } & \multicolumn{2}{c}{$\begin{array}{c}\text { Unstandardized } \\
\text { Coefficients }\end{array}$} & $\begin{array}{c}\text { Standardized } \\
\text { Coefficients }\end{array}$ & \multirow{2}{*}{ t } & \multirow{2}{*}{ Sig. } \\
\cline { 3 - 5 } & & $\mathbf{B}$ & \multicolumn{1}{c}{ Std. Error } & Beta & & \\
\hline 1 & (Constant) & 1.455 & 1.168 & & 1.245 & .216 \\
& $\begin{array}{l}\text { Efektivitas } \\
\text { dari }\end{array}$ & .512 & .039 & $\mathbf{. 8 0 2}$ & $\mathbf{1 3 . 0 7 1}$ & $\mathbf{. 0 0 0}$ \\
& & & & & \\
\hline
\end{tabular}

a. Dependent Variable: Keputusan membeli konsumen.

Tabel 11. Pengaruh kualitas dan kuantitas komunikasi melalui Instagram secara simultan terhadap efektivitas penyampaian komunikasi pemasaran

ANOVA

\begin{tabular}{llllllr}
\hline & Model & Sum of Squares & df & Mean Square & F & Sig. \\
\hline 1 & Regression & 925.945 & 2 & 462.973 & $\mathbf{8 5 . 0 0 0}$ & $\mathbf{. 0 0 0}^{\mathbf{b}}$ \\
& Residual & 511.993 & 94 & 5.447 & & \\
& Total & 1437.938 & 96 & & & \\
\hline
\end{tabular}

a. Dependent Variable: Efektivitas dari komunikasi

b. Predictors: (Constant), Kuantitas Komunikasi, Kualitas Komunikasi

Diketahui bahwa koefisien determinan $\left(\mathrm{R}^{2}\right)$ pengaruh simultan kualitas dan kuantitas penyampaian komunikasi pemasaran melalui Instagram terhadap efektivitas dari komunikasi sebesar 0.644 sehingga besarnya galat adalah 0.23 . Hal ini memberi arti bahwa sebesar 64.4\% efektivitas penyampaian komunikasi pemasaran dapat dijelaskan oleh keragaman kualitas (kesesuaian konten dengan caption) dan kuantitas (frekuensi pengunggahan) di Instagram. Hasil yang sama terjadi pada koefisien determinan $\left(\mathrm{R}^{2}\right)$ pengaruh efektivitas dari komunikasi melalui Instagram terhadap keputusan membeli konsumen, sehingga sebesara 64.4\% keputusan membeli konsumen dapat dijelaskan dari keragaman efektivitas penyampaian komunikasi pemasaran.

Pada akhirnya keseluruhan model yang menjelaskan hubungan dan pengaruh variabel bebas kualitas dan kuantitas penyampaian komunikasi pemasaran melalui Instagram terhadap variabel intervening (efektivitas penyampaian komunikasi pemasaran) dan pengaruh variabel intervening terhadap variabel terikat (keputusan membeli konsumen) dapat dilihat pada model analisis jalur pada Gambar 5. Dari gambar model jalur dapat dijelaskan bahwa kualitas penyampaian komunikasi pemasaran berupa konten yang menarik dan sesuai dengan informasi yang disampaikan serta frekuensi pengunggahan konten baru dapat dikatakan efektif sebagai penyampaian komunikasi pemasaran dalam menyampaikan informasi mengenai perusahaan Negri Kopi, varian produk kopi yang dihasilkan, tempattempat yang dapat diakses konsumen. Pada akhirnya penyampaian komunikasi pemasaran yang efektif dapat membuat konsumen memutuskan untuk membeli. Terdapat galat sebesar masing-masing 0,37 pada pengaruh kualitas dan kuantitas komunikasi melalui Instagram terhadap efektivitas penyampaian komunikasi

\begin{tabular}{lrr}
\hline EFEKTTIVITAS & \multicolumn{2}{r}{ PENYAMPAIAN } \\
KOMUNIKASI & PEMASARAN & MELALUI \\
INSTAGRAM & DAN & DAMPAKNYA \\
TERHADAP & KEPUTUSAN & MEMBELI \\
KONSUMEN NEGRI KOPI SARONGGE
\end{tabular}

ENDAH LISARINI dan ALIF LAZUARDI 
pemasaran maupun pada pengaruh efektivitas dari komunikasi pemasarn terhadap keputusan membeli konsumen. Hal-hal lain yang tidak diteliti namun menyebabkan galat di antaranya adalah adanya media komunikasi sosial lain yang lebih menarik untuk diikuti, waktu pengunggahan yang kurang tepat dan tingkat frekuensi penggungahan konten baru.

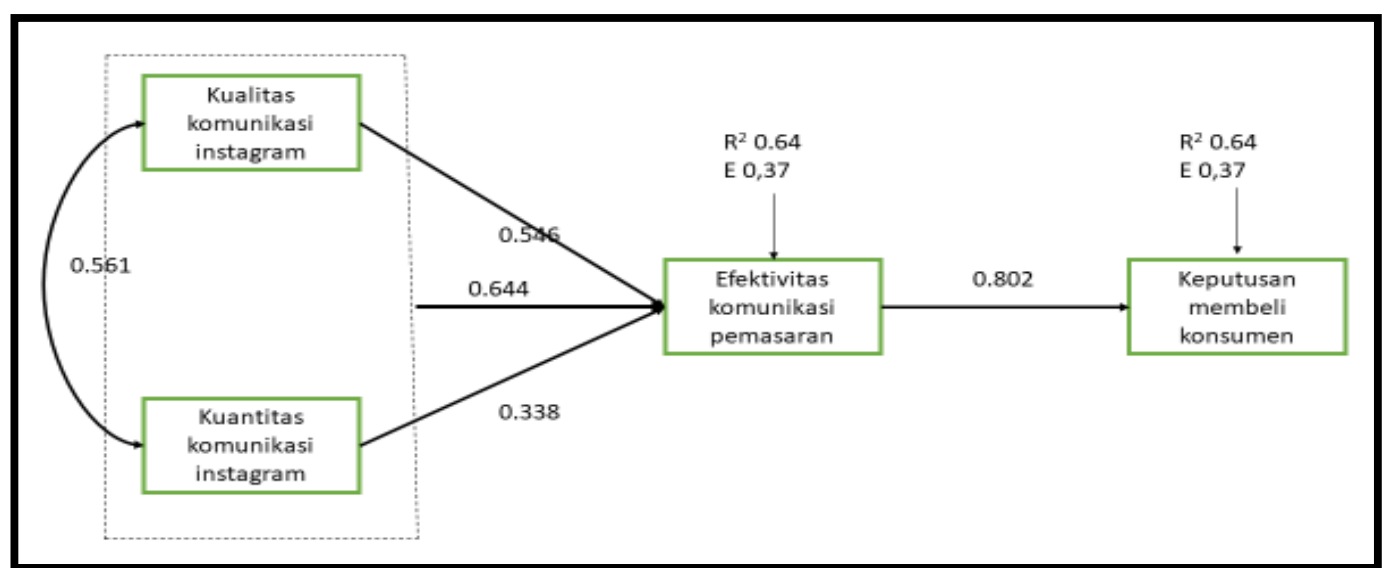

Gambar 5. Model Jalur hubungan dan pengaruh kualitas dan kuantitas penyampaian komunikasi pemasaran melalui instagram secara parsial dan simultan terhadap efektivitas penyampaian komunikasi pemasaran dan dampaknya pada keputusan membeli konsumen.

\section{KESIMPULAN}

Pembahasan dan interpretasi terhadap hasil penelitian memberikan kesimpulan sebagai berikut : 1) kualitas penyampaian komunikasi pemasaran melalui Instagram secara parsial berpengaruh signifikan terhadap efektivitas penyampaian komunikasi pemasaran; 2) kuantitas penyampaian komunikasi pemasaran melalui Instagram secara parsial berpengaruh signifikan terhadap efektivitas penyampaian komunikasi pemasaran; 3) kualitas dan kuantitas penyampaian komunikasi pemasaran secara simultan berpengaruh signifikan terhadap efektivitas penyampaian komunikasi pemasaran; 4) efektivitas penyampaian komunikasi pemasaran berpengaruh signifikan terhadap keputusan membeli konsumen Negri Kopi.

\section{DAFTAR PUSTAKA}

Anonim. (2010). Panduan Memilih Koneksi Internet Unttuk Pemula. Jubilee Enterprise. Elex Media Komputindo:Jakarta.

Anonim. (2018). Survei APJII : Penetrasi Internet Di Indonesia. Buletin. Asosiasi Penyelenggara Jasa Internet Indonesia:Jakarta.

Arikunto, S. (2006). Prosedur Penelitian Suatu Pendekatan Praktik.(Edisi Revisi VI). PT. Rineka Cipta: Jakarta.

Clow, Kenneth \& Back, Donald. (2014). Integrated Advertising, Promotion, and Marketing Communications. Pearson Education South Asia Pte Ltd.

\begin{tabular}{|c|c|c|}
\hline$\overline{\text { EFEKTTIVITAS }}$ & PENYAMPAIAN & $\overline{\text { ENDAH LISARINI dan ALIF LAZUARDI }}$ \\
\hline KOMUNIKASI & PEMASARAN & \\
\hline INSTAGRAM & DAMPAKNYA & \\
\hline TERHADAP & KEPUTUSAN & \\
\hline
\end{tabular}


Dwinanda, Januariska Bayu; Ninuk Purnaningsih. (2018). Efektivitas Penyampaian komunikasi pemasaran Personal Selling Pada Agrowisata Kampung 99 Pepohonan. Jurnal Komunikasi Pembangunan. Vol. 16 No. 02.

Edhole. (2013). Marketing Management. Volume I - IV. Education Hole.

Ghozali, Imam. (2018). Analisis Data Untuk Riset Manajemen dan Bisnis. E-book library.

Hanum, Zubaidah, Sahral Hidayat. (2017). Faktor-faktor Yang Mempengaruhi Perilaku Konsumen Dalam Keputusan Pembelian Sepatu Merek Nike Di Kota Medan. Jurnal Bisnis Administrasi. 06 (01):37-43.

Hardjana, Andre. (2000). Audit Komunikasi: Teori dan Praktek, Jakarta: PT Grasindo.

Idana, Muhammad Ikhwanuddin. (2018). Strategi Media Daring Instagram Sebagai Media Promosi Salad Nyoo. Jurnal Al-Misbah. Vol. 06 No. 01.

Kinanti, Syafira Putri, Berlian Primadani S. P. (2017). Pengaruh Media komunikasi sosial Instagram @zapcoid Terhadap Brand Equty Zap Clinic. Jurnal Komunikasi. 09 (01):53-64.

Kotler, Philip; Garry Amstrong. (2008). Prinsip-prinsip Pemasaran. Edisi 1 - 12/E. Penerbit Erlangga. Indonesia. ISBN. 978-979-03

Kotler, P., Kevin L. Keller, Swee Hoon Ang, Siew Meng Leong, Chin Tiong Tan. (2012). Marketing Management. An Asian Perspective. Pearson Education South Asia Pte Ltd.

Nurrahman, Roland an Yuliati. (2019). Efektivitas Media komunikasi sosial Instagram @visitBengkulu Sebagai Media Promosi Pariwisata Provinsi Bengkulu. Jurnal Kaganga. Vol. 03 No. 01.

Olpengujianmi Kayode. (2014). Marketing Communications. 1st edition. ISBN 978-87403-0674-3

Sarastuti, Dian. (2017). Strategi Penyampaian komunikasi pemasaran Online Produk Busana Muslim Queenova. Jurnal Visi Komunikasi. 16(01):71-90.

Setiadi, Ahmad. (2016). Pemanfaatan Media komunikasi sosial Untuk Efektivitas dari komunikasi. Jurnal Cakrawala. Vol. 16., No.02. ISSN 1411-8629, EISSN 25793314.

Solomon, Michael., Gary Bamossy, Soren Askegaaard, Margaret K. Hoog. (2006). Consumer Behaviour. A European Perspective. Prentice Hall. England.

Untari, D dan Fajariana, D.E. (2018). Strategi Pemasaran Melalui Media komunikasi sosial Instagram (Studi Deskriptif Pada Akun@Subur_Batik).Jurnal Widya Cipta. Vol. 02 No.02. Undang-Undang ITE Republik Indonesia. Nomor 11. (2008). Informasi dan Transaksi Elektronik.

Widodo, Prasetyo Budi. (2006). Reliabilitas dan Validitas Konstruk Skala Konsep Diri Untuk Mahasiswa Indonesia. Jurnal Psikologi Universitas Diponegoro. Vol. 3, N0.1.

\begin{tabular}{|c|c|c|}
\hline EFEKTTIVITAS & PENYAMPAIAN & ENDAH LISARINI dan ALIF LAZUARD \\
\hline KOMUNIKASI & PEMASARAN MELALUI & \\
\hline INSTAGRAM & DAMPAKNYA & \\
\hline TERHADAP & KEPUTUSAN MEMBELI & \\
\hline
\end{tabular}

